\title{
REDUÇÃO DA INACURÁCIA DAS INFORMAÇÕES DE ESTOQUE DE SOBRESSALENTES EM NAVIOS DE GUERRA COM A UTILIZAÇÃO DA TECNOLOGIA RFID
}

\author{
ROGÉRIO FERRAZ QUEIROZ MIRANDA \\ CECAFA / CIANB \\ rogeriomiranda87@gmail.com \\ DIEGO LOPES DUARTE \\ Universidade Federal Fluminense (UFF) / CIANB \\ dlduarte@id.uff.br
LUIZ CARLOS MAGALHÃES RIBEIRO
CIANB \\ luizcarlosmr@gmail.com
}

MARCELO REIS BZERRA

Marinha do Brasil / PUC-Rio

marceloreisbezerra@gmail.com

\begin{abstract}
Resumo. Atualmente, as organizações buscam satisfazer as necessidades de clientes e aumentar a eficiência da cadeia de suprimentos. Nesse sentido, a inacurácia das informações de estoque desafia estes objetivos ao causar a redução do nível de serviço e o aumento de custos operacionais. Setores públicos e privados adotam tecnologias inovadoras, visando mitigar tal inacurácia. Portanto, será examinada a contribuição da Identificação por Radiofrequência (Radio Frequency Identification - RFID) no incremento da acuracidade de estoque de sobressalentes em navios de guerra, contribuindo para maior eficiência logística de meios operativos empregados na Base de Defesa da Amazônia Azul. O Retorno sobre Investimento (Return on Investment - ROI) de aproximadamente 67,63 demonstra que a solução proposta é viável e eficaz.
\end{abstract}

Palavras-chaves: RFID; Inacurácia de Estoque; Cadeia de Suprimento; Sobressalentes.

Abstract. Nowadays, organizations seek to satisfy their customers' needs and to increase the efficiency of the supply chain. In this sense, the inaccuracy of the inventory information defies these goals by causing the reduction of the service level and the increase of the operational costs. Public and private sectors use innovative technologies, aiming to mitigate the inaccuracy. However, the contribution of Radio Frequency Identification (RFID) will be examined in increase of the spare parts inventory accuracy in warships, contributing for a higher logistic efficiency of the operative means used in Blue Amazon Base of Defense. The Return of Investment (ROI) of approximately 67.63 demonstrates that the proposed solution is viable and effective.

Keywords: $\quad$ RFID. Inaccuracy of inventory. Supply Chain. Spare Parts. 


\section{INTRODUÇÃO}

Em face do cenário internacional, no qual o Brasil destaca-se como potência emergente, é imperativo que as Forças Armadas pátrias acompanhem o mesmo ritmo de evolução tecnológica de Forças singulares ao redor do mundo, constituindo uma Base Sólida de Defesa da Amazônia Azul. Ademais, é crescente a demanda por navios em operações no país e no exterior, alçando a bandeira nacional na defesa de interesses do Estado.

Desta feita, são almejados o aperfeiçoamento da gestão de estoques e o aprimoramento de ferramentas de monitoramento de estoques de sobressalentes. Tais requisitos logísticos estão relacionados com o grau de acurácia das informações de estoques imobilizados em navios, cuja utilização se dá na condução de manutenções preventivas e corretivas de equipamentos e sistemas a bordo. A disponibilidade de estoques de sobressalentes é relevante para a eficiência logística de cada navio. Neste sentido, justifica-se o estudo da aplicação de Tecnologia da Informação (TI) com vistas a incrementar a acurácia das informações de estoques dos sobressalentes na cadeia de abastecimento.

Logo, a entrega de melhores resultados à sociedade brasileira sob a busca da eficiência, da otimização do emprego de ativos e da redução de custos indesejáveis ao longo da cadeia de suprimentos, bem como o desenvolvimento logístico de tecnologias utilizadas na consolidação da Base Logística de Defesa da Amazônia Azul tornam-se necessários.

Nesse viés, este estudo tem como objetivo geral examinar a adoção da tecnologia de Identificação por Radiofrequência (Radio Frequency Identification - RFID) como uma ferramenta inovadora aplicada à gestão dos processos logísticos a bordo de navios de guerra, visando ao incremento da acurácia do inventário físico na cadeia de suprimentos de sobressalentes da MB.

No âmbito internacional, existe a perspectiva que o Brasil se torne o principal ator na aplicação da tecnologia RFID tanto no setor público quanto no setor privado [1]. Além disso, há uma carência de pesquisas sobre o problema da acuracidade de estoque e de desenvolvimento acerca de soluções inovadoras destinadas a combater os malefícios deste fenômeno no país [2].

Essa pesquisa também tem os seguintes objetivos específicos, a saber: descrever e avaliar o modelo atual dos processos logísticos de inventário cíclico de estoques de sobressalentes a bordo das Fragatas Classe Niterói, e verificar de que forma o modelo futuro (com a aplicação da tecnologia RFID em itens de sobressalentes) impactará a acurácia das informações de estoques dos sobressalentes das Fragatas Classe Niterói, sob o foco da análise financeira por meio do Retorno sobre Investimento (Return on Investment - ROI).

Como deflagradora de representativos custos na cadeia de suprimentos de sobressalentes, tem-se a deficiente acurácia das informações de estoques dos sobressalentes armazenados em navios de guerra, causada por erros de transação, por perdas de itens e por inacessibilidade de estoques, acarretando óbices na eficiência logística de navios de guerra [3; $4 ; 5 ; 6 ; 7]$.

Nas próximas sessões serão abordados a RFID e sua aplicação em nichos similares ao proposto e a metodologia utilizada neste artigo. Será analisado o estado atual e evidenciado o funcionamento do modelo futuro e seus benefícios, expondo o cálculo do ROI. Finalmente, o artigo detém em sua conclusão sua contribuição e sugestão para futuras pesquisas.

\section{REFERENCIAL TEÓRICO}

\subsection{LOGÍSTICA E GERENCIAMENTO DA CADEIA DE SUPRIMENTOS DE SOBRESSALENTES}

A logística surgiu como componente da guerra, situação da qual extraiu seus ensinamentos essenciais. Embora os combatentes tenham sido autossuficientes nos primórdios das guerras, com o avanço da complexidade do combate, o grupo de militares responsável pela logística era incumbido por abastecer as linhas de frente com os suprimentos necessários 
para o deslocamento tático da tropa [9].

Fruto dos saltos tecnológicos e das exigências de mercado, a gestão de processos logísticos, que outrora eram gerenciados separadamente, passou a ser conduzida de forma integrada. Tais fatores impulsionaram as transformações da logística, culminando na adoção do Gerenciamento da Cadeia de Suprimentos (Supply Chain Management - SCM), conceituado como um conjunto de métodos utilizados para coordenar eficazmente o fornecimento, a armazenagem e os varejistas, com vistas a distribuir bens na quantidade exata, com a qualidade requisitada, no lugar correto e no tempo oportuno [9;10].

A evolução do SCM demandou também o avanço de Sistemas de Informação (SI). Nesse sentido, surgiu o Sistema de Gestão Integrada (Enterprise Resource Planning - ERP) como um SI que integra os nichos de negócios organizacionais, criando valor, mitigando custos e disponibilizando informações consistentes, proporcionando uma melhor tomada de decisão e afiançando uma gestão lucrativa e proativa dentro da cadeia de suprimentos [11].

Outro SI importante para o SCM é o Warehouse Management System (WMS) definido como um Sistema de Gerenciamento de Armazém que aperfeiçoa as atividades operacionais e administrativas, bem como os respectivos fluxos de materiais e informações dentro do processo de armazenagem, incluindo o recebimento, o endereçamento, a armazenagem, a separação e a emissão de documentos para contagem de estoques [12].

O gerenciamento da cadeia de suprimentos de sobressalentes (CSS) é desafiador, Em face das características peculiares atinentes aos itens de reposição. Segundo Khajavi et al. [13], o objetivo perseguido nesta cadeia é a redução dos custos operacionais mantendo os requisitos de nível de serviço ao cliente.

Em 2009, a Defesa nos EUA movimentou 194 bilhões de dólares em operações logísticas e gerenciamento da CSS, sendo 53\% deste valor em suprimentos; $37 \%$ em manutenção e $10 \%$ em transporte [13]. Todos os anos nos EUA um trilhão de dólares são investidos no mercado de sobressalentes e serviços de manutenção, representando, assim, $8 \%$ do PIB americano [14]. Tais valores e percentuais expõem a necessidade de investir em pesquisa no SCM de sobressalentes a fim de minimizar os custos incorridos ao longo da cadeia.

A imprevisibilidade da demanda é também um fator peculiar à CSS, acarretando um ambiente de incerteza [15]. Visando proporcionar o nível de serviço ao cliente, ocorre o acúmulo de estoques ao longo da cadeia, justificando o alto valor de estoque imobilizado [14].

A gestão de armazenagem envolve os processos de recebimento, movimentação, estocagem, separação e expedição do pedido para um cliente. Estas operações ligam estrategicamente clientes a fornecedores, processando não apenas o fluxo de material entre os membros da cadeia [12], mas também contribuindo com o fluxo de informação de toda a cadeia de suprimentos.

Com base na literatura especializada e nas pesquisas conduzidas na $M B$, são exemplificados aspectos que condicionam a complexidade da CSS, a saber: alto custo de capital imobilizado em estoque [14]; demanda errática e intermitente [17]; desatualização do banco de dados de itens de sobressalente; idade e ciclo de vida dos equipamentos [15]; relevante custo de falta; risco e custo de obsolescência [15]; ausência do compartilhamento de informações dos controles de estoques; e deficiente integração entre as Funções Logísticas Manutenção e Suprimento [11].

Tais óbices têm como principais consequências o elevado número de respostas de falta de estoque aos pedidos dos clientes, bem como elevado tempo de atendimento para correção destas falhas [11].

\subsection{O CONTROLE DE INVENTÁRIO E A ACURÁCIA DE INFORMAÇÕES DE ESTOQUE NA CADEIA DE SUPRIMENTOS}

$\mathrm{O}$ processo de controle de inventário conecta a gestão de armazenagem junto à gestão de estoques, efetuando a harmonização entre as necessidades do cliente e as 
disponibilidades de produtos nos Centros de Distribuição (CD), com vistas a garantir o nível de serviço adequado [12]. Dentre as atividades do controle de inventário, destaca-se a realização da contagem cíclica, ou inventário cíclico, que pode ser definida como a verificação de um grupo de itens de material existentes em um $\mathrm{CD}$, cotejando o saldo de estoque físico ante ao contábil. Esta atividade é considerada como uma das ferramentas para se eliminar parcial ou totalmente a inacurácia de informações de estoque [6].

A grande diversidade de itens SKU estocados nos CD de sobressalentes está diretamente relacionada às incorreções decorrentes de divergência entre as quantidades físicas existentes e quantidade contábil registrada [18]. Além disso, a imprecisão das informações entre estoque real e o estoque do SI deteriora o desempenho de toda a cadeia de suprimentos, mitigando os níveis de serviço proporcionados ao cliente final [6;7]; reduzindo a eficiência operacional da cadeia [2]; induzindo erros no planejamento da demanda [2]; e aumentando os custos logísticos de toda a cadeia de abastecimento [3].

Por outro lado, a manutenção da acurácia do inventário em níveis elevados resulta nas seguintes vantagens para toda a cadeia: aumento do nível de serviço ao cliente (coincidência entre estoque físico e contábil); melhoria da determinação de necessidades de ressuprimento; incremento na disponibilidade de itens; e auxílio na análise de excessos e faltas em estoque [2]. A precisão da contagem cíclica pode ser representada pelo percentual de itens que não apresentaram divergências por ocasião da realização de uma contagem física, em relação à quantidade total contabilizada.

Embora apontem o avanço da captura de dados ao longo da cadeia de abastecimento, como, por exemplo, o intercâmbio eletrônico de dados (Electronic Data Interchange - EDI), é frequente a discrepância entre dados de demanda do consumidor final ou níveis de estoques nos SI versus o fluxo físico real de material na cadeia de suprimentos $[3 ; 4 ; 5 ; 7 ; 19]$.

DeHoratius e Raman [20] registram estudos de caso nos quais o fenômeno supracitado resultou na diminuição de $25 \%$ do faturamento de organizações. Para os autores, as seguintes causas são responsáveis pela inconsistência das informações apresentadas nos SI: furtos; produtos que não podem ser vendidos (deteriorados e obsoletos); dados de recebimento e expedição incorretos; e perda de produtos.

Segundo Sarac et al. [7], as causas da inacurácia das informações de estoque são semelhantes às elencadas por Fleisch e Tellkamp [5]. Após pesquisarem durante 37 anos, sobre as causas da inacurácia de inventário, Sarac et al. [7] concluem as seguintes causas: erros de transação, perdas de itens e inacessibilidade de estoques no varejo.

Os fatores conciliados à pesquisa deste artigo serão descritos a seguir:

a) os erros de transação incluem: (i) erros de expedição (são os mais caros por envolver o custo de transporte da logística reversa) [3]; (ii) erros de recebimento (discrepância entre as quantidades fornecidas e as quantidades solicitadas) [7]; (iii) erros de leitura (quando um consumidor desejar obter dois itens com o mesmo preço e para tornar a compra mais célere, é registrada saída de um produto em detrimento do produto verdadeiro);

b) as perdas de itens representam 1,69\% das vendas do varejo, conforme Sarac et al. [8]. O furto de funcionários, os erros administrativos, os furtos em lojas, as fraudes de fornecedores e produtos que não podem ser vendidos fazem parte desta categoria;

c) a inacessibilidade de estoques é o endereçamento incorreto do material por ocasião de sua armazenagem em localização distinta da registrada no SI, tornando o produto inacessível quando demandado [21];

d) erros na contagem de estoques, a condução ineficiente da contagem física, reproduzindo no SI quantidades e itens SKU inconsistentes com o estoque físico [2]; e

e) erros na identificação, a identificação incorreta do item resulta no registro equivocado do material por ocasião de sua movimentação e armazenagem [21].

\subsection{A TECNOLOGIA RFID E SUA APLICAÇÃO EM GESTÃO DE ESTOQUES}

O RFID é uma pequena etiqueta que contém um chip com circuito integrado, com 
memória e uma antena, capaz de responder a ondas de rádio transmitidas por um leitor RFID a fim de enviar, processar e estocar informação [11]. A troca de dados por meio de radiofrequência permite maior rastreamento de material e visibilidade ao longo de toda a cadeia de abastecimento, reduzindo custos, aumentando a receita e incrementando os processos e a qualidade dos serviços $[22 ; 23 ; 24]$.

O sistema RFID é composto por cinco componentes básicos [16; 25]: tag, permite a identificação de produtos; leitor, capta as ondas de rádio emitidas por uma ou mais antenas e recebidas de volta da etiqueta, transformando a informação em formato digital; antena, possibilita a troca ou envio de informações entre o tag e o leitor; middleware RFID, utilizado pelo leitor para enviar a um SI os dados capturados da etiqueta, por meio de infraestrutura de comunicação; e SI, processando os dados capturados por meio de computadores ou até mesmo sistemas integrados em rede.

A literatura especializada relata os benefícios advindos da adoção de tag RFID no nível de item em todos os produtos dentro da cadeia de suprimentos, independentemente do valor monetário do item [26]: aperfeiçoamento da gestão de estoques, com o aumento da acurácia de estoques [2]; pouca ou nenhuma interface manual para coleta de dados; redução da necessidade de força de trabalho (mão de obra); aumento da visibilidade de estoques; e aumento da facilidade de estocagem (correta identificação do local de armazenagem) e de reabastecimento [11].

Os sobressalentes dos navios de guerra da MB são constituídos, em sua maioria, de itens metálicos e armazenados a bordo em ambientes também metálicos. Estas premissas dialogam com a literatura sobre os efeitos negativos de sistemas RFID operando sob aqueles requisitos: a reflexão da energia para longe da etiqueta e o desajuste da antena da etiqueta, ambos concorrendo para a diminuição das taxas de leitura [27].

Embora existam tais empecilhos, a demanda pela utilização de projetos RFID para a gestão de ativos e o controle de estoques de equipamentos e produtos feitos de metais impulsionaram o desenvolvimento de soluções para estes fins. Bauer-Reich et al. [27] propõem a utilização de etiquetas on-metal em materiais de superfície metálica. Este projeto foi desenvolvido entre a Universidade da Dakota do Norte e a Marinha dos EUA para o programa Tecnologia de Identificação Automática, ou (Automatic Identification Techonology - AIT), do Departamento de Defesa Norte-Americano.

A aplicação da solução RFID para o incremento da eficiência de inventário cíclico na camada varejista tem sido divulgada pela literatura acadêmica $[12 ; 22 ; 23]$. Nestes casos, propõe-se o ataque das causas da inacurácia das informações de estoques na cadeia de suprimento por meio da captura automática de dados em tempo real, mitigando e detectando erros de registros de estoques ao longo da cadeia $[3 ; 4 ; 5 ; 7 ; 21]$.

Isto posto, Fan et al. [4] propõem o uso da RFID para reduzir as perdas de itens em dois cenários distintos: o incremento do processo de inventário cíclico na camada varejista com RFID e sem RFID. No modelo com RFID, os autores demonstram considerável incremento da eficiência aliado à alta taxa de leitura e disponibilidade de estoques.

Fleisch e Tellkamp [5] sugerem a utilização da pesquisa sobre a acuracidade de estoques em organizações que possuem considerável nível de erros de registro de estoque com vistas a escolher a tecnologia ideal para eliminar ou reduzir os efeitos indesejáveis. Os autores sublinham o potencial da tecnologia RFID no incremento da acurácia de estoque no varejo em busca da redução de custos logísticos e da ruptura de estoques.

Ao estudarem a aplicação RFID em um complexo sistema de distribuição de suprimentos para varejistas, Goebel e Günther [28] demonstram o benefício proporcionado da total visibilidade de estoques na camada do varejo. Os mesmos autores expõem a redução do custo total do sistema entre $7 \%$ e $74 \%$, em função do número total de origem de erro (desvios, perdas, erros de processamento, processos de recebimento não confiáveis e problemas de qualidade). 
Em um ambiente de alto nível de incerteza da demanda e em função do grau de discrepância de informações de estoques, Sari [29] evidencia uma redução no custo total da cadeia de abastecimento entre aproximadamente 3\% e $29 \%$, após a adoção da tecnologia RFID. Estes percentuais tendem a aumentar, pois aqueles custos logísticos não contabilizam o custo de manutenção de estoques. Desta maneira, Hellström e Wiberg [19] afirmam que a tecnologia RFID oferece solução para os efeitos indesejáveis da inacurácia, incluindo os altos custos de estoques.

Uma cadeia de suprimentos Multi-Escalão é modelada contendo informações incorretas de estoques em cada camada e com política específica de inventário cíclico [6]. A RFID encontra sua utilidade ótima na camada varejista ao apoiar os processos de contagem cíclica, proporcionar maior confiabilidade e rapidez e reduzir custos. Os autores provaram a maior eficiência do inventário cíclico na camada varejista.

Quanto à aplicação da tecnologia, a Marinha Americana ampliou o uso da RFID para o rastreamento de itens de sobressalentes empregados a bordo dos Navios de Combate Litorâneo (Littoral Combat Ships - LCS). A solução RFID prevê a eliminação integral de contagens manuais de estoques a bordo, bem como emprega etiquetas RFID em cada item metálico armazenado também em armários metálicos dentro de contentores embarcados nos navios. Até mesmo com navio em operação no mar, ocorre a captura de dados de localização das etiquetas em tempo real [30].

O projeto de RFID nos LCS prevê a economia de 14 milhões de dólares em custos de mão de obra empregada na realização de inventário cíclico. Em dez anos, culminará no ROI de $3.000 \%$. Ademais, a solução promove a acurácia de estoque de $99 \%$, a redução do montante de trabalho para realizar a contagem de estoque em quase $100 \%$ e do tempo empregado em contagem física de $87 \%$ [30].

A MB também iniciou o projeto de automação do inventário físico da cadeia de suprimentos de fardamento. No primeiro momento, a infraestrutura necessária da tecnologia RFID no Depósito de Fardamento da Marinha no Rio de Janeiro será mapeada. O aumento da acuracidade de estoque é uma das metas almejadas no projeto da MB.

Como método de avaliação financeira da aplicação da tecnologia RFID, a literatura acadêmica consagra o ROI, uma medida de avaliação de investimentos em novas tecnologias para uma organização, em especial, para o estudo de viabilidade de implementação da tecnologia RFID dentro de uma determinada moldura temporal [23].

\section{METODOLOGIA}

Conforme Gil [31], este estudo é classificado segundo sua finalidade e seus objetivos em pesquisa exploratória, pois constrói informações mais ampliadas acerca da utilização da tecnologia RFID na gestão da cadeia de suprimentos de sobressalentes; em pesquisa aplicada, pois gera conhecimentos aplicáveis na solução de problemas específicos; e em pesquisa descritiva ao analisar o modelo atual sob a descrição das características dos processos logísticos aplicados à cadeia de suprimentos de sobressalentes a bordo de navios de guerra.

Em se tratando dos métodos empregados, esta pesquisa é classificada como pesquisa bibliográfica, documental e estudo de caso [31]. Pesquisa bibliográfica que tem como fundamentação teórica a investigação acerca da cadeia logística de sobressalentes e da tecnologia de RFID em livros e publicações periódicas. Pesquisa documental, uma vez que expõe informações atinentes à organização (relatórios, planilhas de custos, sistemas de informação, entre outros) coletadas entre janeiro e setembro de 2014. Por fim, estudo de caso porque avaliará o caso de aplicação da tecnologia de RFID na cadeia de suprimentos de sobressalentes, objetivando aliar a fundamentação teórica com a prática.

O estudo de campo foi conduzido, por meio de entrevistas não estruturadas, aos militares responsáveis pela gestão de estoques de sobressalentes lotados nos navios e nas Organizações Militares do Sistema de Apoio Logístico, propiciando a coleta de dados 
necessários. As observações espontâneas foram fontes de evidências adicionais, proporcionando a inserção no ambiente estudado.

\section{ANÁLISE DO MODELO ATUAL E DO MODELO FUTURO}

\subsection{MODELO ATUAL DA CADEIA DE SUPRIMENTOS DE SOBRESSALENTES: SEM RFID}

As Fragatas Classe Niterói (FCN) são seis navios-escolta empregados em operações navais na Amazônia Azul e em águas internacionais, tais como Líbano, África do Sul, Reino Unido, entre outras [32]. Portanto, esta pesquisa é limitada à cadeia de suprimentos das FCN por sua importância estratégica, pelo montante financeiro imobilizado em estoque de sobressalentes em cada navio e por cada navio que apresenta configurações semelhantes de sistemas e equipamentos entre si [11].

O principal fornecedor das FCN é o Sistema de Abastecimento da Marinha (SAbM), que opera toda a CSS com Órgãos especializados em função das respectivas fases da logística: determinação de necessidades, obtenção e distribuição. Cada item SKU de sobressalente pertencente à linha de fornecimento do SAbM é identificado por meio de seu NATO Stock Number (NSN), isto é, uma numeração que contém treze dígitos numéricos e identifica inequivocamente um sobressalente ante às nações pertencentes ao Sistema OTAN de Catalogação.

Toda fragata é atrelada a um conjunto específico de equipamentos e sobressalentes que são denominados de Lista de Dotação Integrada (LISDIN) e identificados pelos NSN, compondo uma estrutura sequencial, começando pelo mais alto nível (sistema) e descendo a estrutura (equipamentos e sobressalentes), resultando na lista de sobressalentes por equipamento no decomposta de cima (sistemas) para baixo (peças). Ao longo do ciclo de vida do navio, por requisitos operativos e técnicos, a LISDIN sofre modificações em função da inclusão ou exclusão de equipamentos e sobressalentes na configuração de sistemas e equipamentos de cada navio.

Por meio de EDI, os pedidos de itens de sobressalente são lançados diretamente no WMS SISBORDO Sobressalentes e autorizados previamente por militar pertencente ao Departamento de Intendência existente em cada navio. Tal Departamento executa a gestão de estoques e armazenagem dos sobressalentes armazenados. Portanto, o Departamento de Intendência de cada fragata deve ser considerado um varejista perante os outros três Departamentos existentes no navio, denominados como consumidores finais: Departamento de Máquinas, de Armamento e de Operações.

Caso, a bordo, não haja disponibilidade do sobressalente solicitado, por meio de um WMS chamado SISBORDO, o pedido será enviado ao SAbM. Este analisará e aprovará, ou não a requisição, em função do nível de estoque no $\mathrm{CD}$ principal. $\mathrm{O}$ pedido emitido pelo navio assumirá a condição de "em dívida" quando não for atendido por falta de disponibilidade de estoque. Do contrário, o CD cumprirá suas programações de entregas aos navios. Após o recebimento de itens solicitados, o material é acondicionado em um dos seis armazéns alocados em cada navio.

Com o uso progressivo dos equipamentos e sistemas de bordo das fragatas, naturalmente emergem necessidades de reposição de sobressalentes, seja por manutenção corretiva ou manutenção preventiva. É evidente que tais necessidades são conhecidas pelo SAbM por meio de pedidos inseridos. Nesse sentido, extraído do SISBORDO, o valor de estoque imobilizado a bordo de todas as FCN monta R\$ 61.104.783,53. Há também 55.510 NSN (itens SKU) e 66.580 endereçamentos de armazéns registrados no SISBORDO [11].

A título de comparação, o CD principal possui 600 milhões de reais em estoques de sobressalentes, sendo 26 milhões de reais o valor de fornecimento médio anual nos últimos cinco anos. Em termos financeiros, os navios possuem em seus armazéns sobressalentes suficientes para abastecer os meios navais, aeronavais e de fuzileiros navais de toda a MB 
durante dois anos, detendo $10 \%$ do valor contábil de itens de sobressalentes estocados no CD.

Os supracitados valores e percentuais analisados em conjunto, com base nas entrevistas realizadas pelo estudo de campo, ratificam a importância de um eficiente controle de estoque a bordo das FCN visando à automação de processos logísticos de suprimentos no "varejo", ao aumento da acuracidade de estoque e à redução do capital humano envolvido nas operações de armazenagem a bordo de cada navio.

Cabe ressaltar que o armazenamento de sobressalentes demandados em avarias inopinadas de equipamentos críticos ou em condução de manutenção planejada atende ao requisito de permanência no Teatro de Operação Marítimo.

O modelo atual prevê a realização de contagens cíclicas como uma apuração rotativa, contínua e seletiva da dotação de bordo de sobressalentes existentes nos navios a fim de que todos os itens sejam verificados anualmente.

Neste processo, foram observados os seguintes aspectos: a comissão responsável pelo inventário cíclico o conduz acumulando com outras responsabilidades afetas às atividades operativas do navio; a comissão sofre com a descontinuidade de conhecimento e o alto grau de rotatividade dos militares embarcados; a contagem desloca de suas atividades-fim a mão de obra especializada a bordo; o inventário cíclico é totalmente manual, dependendo da contagem física, escrituração em rascunho e posterior lançamento no SISBORDO (caso haja alguma discrepância); e a contagem de grande quantidade de itens SKU.

Como resultado dos aspetos citados, percebe-se a acuracidade de estoque em média de $85 \%$ verificada na camada varejista, a partir de observações de compatibilidade entre o saldo de estoque registrado no WMS e o relatado fisicamente. As diferenças são constatadas durante a separação de um pedido urgente emitido por outro navio da mesma classe.

Este índice não foge ao contexto do mercado privado, onde somente $31 \%$ de empresas brasileiras de médio porte apresentam os dados confiáveis de acuracidade de estoque [2]. Já no mercado internacional, é percebida acuracidade de 35\% [18].

O inventário cíclico é realizado por meio da contagem física de em média onze mil localizações, comparando o saldo de estoque no SISBORDO com o existente fisicamente. Devem ser verificadas as condições das embalagens de cada item; se o item é obsoleto, recuperável, antieconômico ou inservível; e se há a necessidade de substituição das etiquetas com código de barras do CD principal para a aposição manual de etiqueta de identificação.

Atualmente, o inventário cíclico despende elevado tempo em função dos diversos itens e posições existentes a bordo. O militar deve checar cada material e transcrever manualmente em papel para depois lançar no SISBORDO, contabilizando item por item.

Com formato semelhante ao inventário cíclico, o Programa de Organização de Sobressalentes (POSE) é realizado nas fragatas no Período de Manutenção Geral, quando o navio permanece em reparo de aproximadamente quatro anos. O POSE tem por finalidade atualizar o registro de configuração das fragatas e organizar, qualitativa e quantitativamente, os seus sobressalentes.

Fruto de observações espontâneas e entrevistas, observou-se no modelo atual as principais causas geradoras da inacurácia de informações de estoques a bordo: erros de transação provenientes na expedição e no recebimento de sobressalentes a bordo de cada navio; inacessibilidade de estoques ou erros na armazenagem e localização (ausência da rastreabilidade de itens a bordo); erros de contagem de estoque; e erros na identificação (atividade de catalogação).

\subsection{ANÁLISE DO MODELO FUTURO: USO DA RFID}

O inventário cíclico é uma operação de importância vital para toda a cadeia de suprimentos. É necessário minimizar a diferença entre a quantidade de itens contabilmente registrados no SISBORDO e a quantidade física no estoque, observando a localização correta.

Por meio de consulta a provedores especializados na solução RFID, delineou-se uma estrutura para a operação do modelo futuro, incluindo o conjunto de funcionamento de RFID: 
serviços de consultoria e projeto, software RFID, hardware RFID, especificações técnicas, implantação e integração. O valor médio cotado do investimento foi de $\mathrm{R} \$ 1.100 .672,00$ [11].

A estrutura delineada é composta por um portal de quatro antenas, leitor RFID e fonte externa; um portal idêntico na doca de expedição do CD principal (para controles de saída); oito coletores móveis de alta performance de scanner (um por navio e dois no CD); suporte de antenas RFID; cabos para equipamentos RFID e etiquetas RFID. Na estrutura, estão também previstos o apoio à operação (middleware e treinamentos) e a infraestrutura (base de dados do ambiente operacional e redes de comunicação).

As seguintes premissas são inferidas a fim de viabilizarem o modelo futuro, baseadas no delineamento proposto na pesquisa de campo: a integração entre o middleware RFID e o SINGRA; a viabilidade de aplicação da tecnologia RFID em ambiente de navio de guerra [30]; os itens serão fornecidos aos navios com os tags fixados pelo CD; e o sistema de RFID coexistirá com as soluções atuais já adotadas pelo CD (código de barras), porém não utilizadas a bordo [11].

Com o funcionamento do sistema RFID, por ocasião da contagem cíclica, a equipe realizará a checagem de itens armazenados dentro de cada localização, sem delinear os diferentes itens, pois o militar poderá abrir o software e começar uma pesquisa, considerando todos os sobressalentes em uma única localização a bordo de um navio definido.

O cadastramento de cada item de sobressalente será conduzido com base na LISDIN de cada fragata, possibilitando a identificação inequívoca de cada item e indicando as modificações da configuração de sistemas e equipamentos ao longo do ciclo de vida de cada navio. Estes requisitos são necessários no alcance da rastreabilidade e da visibilidade de equipamentos e sobressalentes, seguindo a abordagem do Life Cycle Management [22].

O sistema poderá emitir instrução para os leitores e exibir uma lista de sobressalentes alocados àquela localização. Os dados coletados deverão ser filtrados por um middleware e enviados ao SISBORDO para subsidiar a tomada de decisão acerca de operações de armazenagem.

No caso específico do inventário cíclico, as seguintes informações poderão ser analisadas: localização de espaço disponível, NSN e respectivas quantidades estocadas a bordo e seu local exato.

Portanto, em face da acurácia de estoque apresentada pelo inventário cíclico após a adoção da RFID, bem como pela possibilidade de condução em maior frequência do inventário, com resultados on-line e real time sobre os estoques acumulados a bordo, a condução da contagem física de sobressalentes durante o POSE não será mais necessária.

Em face da solução proposta para este processo, o benchmarking mais próximo da realidade da MB é a utilização do sistema RFID a bordo dos LCS já apresentado [30].

A acuracidade de estoque no modelo futuro poderá atingir $99 \%$. Tal percentual, em cada navio, significará aumento do nível de serviço; melhoria da determinação de necessidades de ressuprimento; incremento na disponibilidade de itens; auxílio na análise de excessos e faltas de estoque; controle de obsolescência e redução dos custos totais na cadeia de suprimentos.

A redução do tempo de fornecimento de pedidos também ocorrerá em virtude do aumento da disponibilidade em estoque dentro dos próprios navios. Assim, será também incrementando o atendimento de pedidos "em dívida" a partir de estoques disponíveis de outros navios da mesma classe. Esta possibilidade aumenta o nível de serviço em $22 \%$, caso haja uma confiável acuracidade de informações de estoque [11].

O valor de $\mathrm{R} \$ 51.939 .066,00$ é o atual e considerado sob o percentual de $85 \%$ de acuracidade de estoque, com base no valor total de estoque para os seis navios de R\$ 61.104.783,53. Com a acurácia de 99\%, quase a totalidade de itens de sobressalentes disponíveis nos estoques dos seis navios antes não visíveis, o valor futuro será de $\mathrm{R} \$$ 60.493.735,69. Ao subtrair o valor do modelo atual pelo futuro, tem-se o ganho em 
visibilidade com o modelo futuro de $\mathrm{R} \$ 8.554 .669,69$, considerando os seis navios.

Não obstante a visualização do montante financeiro em estudo na realidade da MB, DeHoratius e Raman [20] e Lee et al. [21] demonstram que a inacurácia das informações de estoque representa financeiramente $28 \%$ de todo o valor de inventário físico existente na camada varejista. No caso da MB considerado neste artigo, o percentual é de 16,47\%.

\subsection{ANÁlISE DO ROI NO MODELO FUTURO}

Conforme a Equação 1, calculou-se o ROI com base no ganho monetário (variável "B") subtraído do valor médio valor médio orçado para a estrutura do modelo futuro nas seis fragatas (variável "C"). Semelhantemente à escolha de Chen et al. [23], a taxa básica de juros Selic (variável "i") fixada em $11 \%$ ao ano foi considerada como custo do capital [33]. A moldura temporal foi de dez anos (variável "n"), por ser o possível tempo de vida útil das FCN.

$$
\text { ROI }=\frac{\sum_{t=0}^{n} \frac{B_{t}-C_{t}}{(1+i)^{t}}}{\sum_{t=0}^{n} \frac{C_{t}}{(1+i)^{t}}}
$$

Com base no ganho monetário do incremento da visibilidade de estoque, o ROI é positivo e alcança o valor de 67,63, sendo o modelo futuro eficaz e viável economicamente [23]. Para a mesma moldura temporal, o projeto da Marinha Americana prevê um ROI de 30 (trinta) calculado somente para um armazém e avaliado como financeiramente viável [30].

\section{CONCLUSÃO}

Historicamente, a MB aplica contínuos esforços com vistas a ultrapassar restrições orçamentárias e alcançar patamar tecnológico de excelência em seus meios - foi assim no projeto e construção das Fragatas Classe Niterói. Nesse viés, propõe-se a adoção do sistema RFID com abordagem transformacional capaz de incrementar a eficiência dos processos de negócio da cadeia de suprimentos da MB. No setor de Defesa, há casos nos quais o sistema RFID é aplicado no controle de estoque de sobressalentes como os projetos da Marinha Americana citados neste artigo.

O permanente foco no atendimento ao cliente operativo norteou o estudo da tecnologia RFID, como uma ferramenta inovadora aplicada à gestão dos processos logísticos a bordo de navios de guerra, visando o incremento da eficiência operacional concernente ao inventário físico de estoques, atingindo, assim, o objetivo geral. Além disso, este artigo alcançou seus objetivos específicos ao descrever e a avaliar o modelo atual de inventário cíclico de estoques de sobressalentes e ao verificar o impacto do modelo futuro na acurácia de estoque dos sobressalentes das FCN.

Por proporcionar exclusivas funcionalidades, mitigando a inacurácia das informações de estoque, constata-se que a RFID é a tecnologia viável para suportar o modelo futuro da cadeia de suprimentos de sobressalentes. Os ganhos financeiros entregues pelo modelo futuro foram ratificados pelo ROI de 67,63.

A contribuição desta pesquisa está em proporcionar à $\mathrm{MB}$, especificamente ao SAbM e a uma parcela considerável do Poder Naval, a execução de boas práticas da gestão moderna de processos de negócios. Com fulcro no melhor resultado entregue à sociedade brasileira, buscando a eficiência, a otimização do emprego de ativos e a redução de custos indesejáveis ao longo da cadeia de suprimentos.

Este estudo serve de base para o desenvolvimento de futuras pesquisas sobre a tecnologia RFID na cadeia de suprimentos militar-naval: o modelo de Previsão, Reabastecimento e Planejamento Colaborativo de estoques (Collaborative Planning Forecasting Replishment - CPFR) aliado à tecnologia RFID, para atender às Forças Navais engajadas em operações relevantes nos cenários nacional ou internacional a fim de permitir maior sincronização entre o planejamento logístico da demanda e a execução do apoio 
logístico durante a operação, contribuindo para o desenvolvimento da Base Sólida de Defesa da Amazônia Azul [29].

\section{REFERÊNCIAS BIBLIOGRÁFICAS}

[1] RFID JOURNAL. Brazil Is Poised to Become a Major Player in RFID. 2014. Disponível em: < http://www.rfidjournal.com/articles/view?12363>. Acesso em: 27 out. 2014.

[2] DROHOMERETSKI, E. Um estudo do impacto das formas de controle de inventário na acuracidade de estoque. Dissertação (Mestrado em Engenharia de Produção e Sistemas). Pontifícia Universidade Católica do Paraná. Curitiba, 2009.

[3] DAI, H.; TSENG, M. M. The impacts of RFID implementation on reducing inventory inaccuracy in a multi-stage supply chain. International Journal Production Economics v. 139, n. 2 , p. $634-641,2012$.

[4] FAN, T. J., CHANG, X. Y., GU, C. H., Yi, J. J., DENG, S. Benefits of RFID technology for reducing inventory shrinkage. International Journal Production Economics v. 147, n. 2, p. 659 - 665, 2014.

[5] FLEISCH, E.; TELLKAMP, C. Inventory inaccuracy and supply chain performance: a simulation study of a retail supply chain. International Journal Production Economics, v. 95, n. 3, p. 373 - 385, 2005.

[6] KÖK, A. G.; SHANG, K. H. Evaluation of cycle-count policies for supply chains with inventory inaccuracy and implications on RFID investments. European Journal of Operational Research, v. 237, n.1, p. $91-105,2014$.

[7] SARAC, A.; ABSI, N.; DAUZÈRE-PÉRÈS, S. A literature review on the impact of RFID technologies on supply chain management. International Journal of Production Economics, v. 128, n. 1, p. 77 - 95, 2010.

[8] ISLAM, D. M. Z., MEIER, J. F., ADITJANDRA, P. T., ZUNDER, T. H., PACE, G. Logistics and supply chain management. Research in Transportation Economics, v. 41, n. 1, p 3-16, 2013.

[9] RUSSEL, S. H. Supply chain management: more than integrated logistics. Air Force Journal Logistics, v. 35, n. 3-4, p. 80 - 89, 2011.

[10] SIMCHI-LEVI, D., KAMINSKI, P., SIMCHI-LEVI, E. Designing and Managing the Supply Chain: Concepts, Strategies and Case Studies. 3 Ed. McGraw-Hill, 2008. 544 p.

[11] MIRANDA, R. F. Q. Aplicação da tecnologia RFID na cadeia de suprimento de sobressalentes: um estudo de caso em navios da Marinha do Brasil. Dissertação (Mestrado em Engenharia de Produção). Pontifícia Universidade Católica do Rio de Janeiro. Rio de Janeiro, 2014.

[12] LIM, M. K.; BAHR, W.; LEUNG, S. C. RFID in the warehouse: a literature analysis (1995-2010) of its applications, benefits, challenges and future trends. International Journal Production Economics, v. 145, n. 1, p. 409 - 430, 2013.

[13] KHAJAVI, S. H.; PARTANEN, J.; HOLMSTROM, J. Additive manufacturing in the spare parts supply chain. Computers Industry, v. 6, n. 5, p 50 - 63, 2014.

[14] KARSTEN, F.; BASTEN, R. J. I. Pooling of spare parts between multiple users: How to share the benefits? European Journal of Operational Research, v. 233, n. 1, p $94-104$, 2014.

[15] FAN, C. -Y.; FAN, P.-Y.; CHANG, P.-C. A system dynamic modeling approach for a military weapon maintenance supply system. International. Journal Productions Economics, v. 128, n.2, p. $457-469,2010$. 
[16] WU, N. C.; NYSTROM, M. A.; LIN, H. C. Y. Challenges to global RFID adoption. Technovation, v. 26, n. 12, p.1317 - 1323, 2006.

[17] MOON, S.; HICKS, C.; SIMPSON, A. The development of a hierarchical forecasting method for predicting spare parts demand in the South Korean Navy: a case study. International Journal Production Economics, v. 140, n. 2, p. 794 - 802, 2012.

[18] DEHORATIUS, N.; RAMAN, A. Inventory record inaccuracy: An Empirical Analysis. Management Science, v. 54, n. 4, p. 627-641, 2008.

[19] HELLSTRÖM, D. WIBERG, M. Improving inventory accuracy using RFID technology: a case study. Assembly Automation, v. 30, n. 4, p. 345 - 351, 2010.

[20] DEHORATIUS, N.; RAMAN, A. Inventory record inaccuracy: An empirical analysis. Working Paper, University of Chicago, School of Business. Supply Operations, 2004.

[21] LEE, Y. M.; CHENG, F.; LEUNG, Y. T. A quantitative view on how RFID will improve a supply chain, IBM Research Report, p. 1 - 46, 2005.

[22] MUSA, A.; GUNASEKARAN, A.; YUSUF, Y. Supply chain product visibility: Methods, systems and impacts. Expert Systems with Applications, v. 41, n. 1, p. 176 - 194 , 2014.

[23] CHEN, J.; CHENG, C.; HAUNG, P. B. Supply chain management with lean production and RFID application: a case study. Expert System with Application, v. 40, n. 9, p. 3389 - 3397, 2013.

[24] ILIE-ZUDOR, E., KEMÉNY, Z., BLOMMESTEIN, F.V., MONOSTORI, L., MEULEN, A. V. D. A survey os applications and requirements of unique identification systems and RFID techiniques. Computers in Industry, v. 62, n. 3, p 227-252, 2011.

[25] NGAI, E. W. T., MOON, K. K., RIGGINS, F. J., CANDACE, Y. Y. RFID research: an academic literature review (1995-2005) and future research directions. International Journal Production Economics, v. 112, n. 2, p. 510-520, 2008.

[26] PIRAMUTHU, S.; WOCHNER, S.; GRUNOW, M. Should retail stores also RFID-tag 'cheap' items? European Journal of Operational Research, v. 233, n. 1, p. 281 - 291, 2014.

[27] BAUER-REICH, C.; BERGE, L.; REICH, M. Low-profile, high permeability antennaless RFID tags for use on metal objects. In: International Work-Shop on Antenna Technology (iWAT), IEEE, p 32-35, 2012. Arizona, USA. Anais eletrônicos... doi: 10.1109/IWAT.2012.6178391.

[28] GOEBEL, C.; GÜNTHER, O. Benchmarking RFID profitability in complex retail distribution systems. Eletronic Markets, v. 19, n. 2/3, 2009, p. 103 - 114.

[29] SARI, K. Exploring the impacts of radio frequency identification (RFID) technology on supply chain performance. European Journal of Operational Research, v. 207, n. 1, p.174 $183,2010$.

[30] MABRY, R. Automating the Littoral Combat Ship support container inventory process with RFID. In: Annual Conference X RFID JOURNAL LIVE!, 2012, Florida, USA. Anais eletrônicos... Disponível em: $<$ http://www.rfidjournalevents.com/pres_live12.php $>$. Acesso em: 10 mai. 2014.

[31] GIL, A.C. Como elaborar projetos de pesquisas? São Paulo: Atlas, 2002. p. 41-55.

[32] LEAL FERREIRA, E. B.; SANTA RITA, R. A. C. A Esquadra em 2012. Revista Marítima Brasileira, v. 133, n. 4, trimestral, p. 9 - 17, 2013.

[33] BRASIL. Histórico das taxas de juros fixadas pelo Copom e evolução da taxa Selic. 2014. Disponível em: <http://www.bcb.gov.br/?COPOMJUROS>. Acesso em: 10 set. 2014. 